\title{
Mycelium-bound lipase from a locally isolated strain of Aspergillus flavus link: pattern and factors involved in its production
}

\begin{abstract}
Aspergillus flavus produces a lipase (EC 3.1.1.3) which is partly bound to the mycelium during growth. The production of the mycelium-bound lipase is concomitant with growth, and declines when growth ceases. Maximum productivity of the enzyme is obtained when the culture is incubated at $30^{\circ} \mathrm{C}$, an initial culture $\mathrm{pH}$ of 6.5 and with $2 \%(\mathrm{w} / \mathrm{v})$ each of corn oil and yeast extract as carbon and organic nitrogen source. Yeast extract affects not only the production of lipase but also the secretion of proteases into the culture medium. Production of the latter enzymes, which inactivate the free lipase, is enhanced by adding yeast extract (1ï $2 \%, \mathrm{w} / \mathrm{v})$ to the culture medium. However, at $5 \%(\mathrm{w} / \mathrm{v})$ yeast extract concentration, proteolytic activity is not detected and consequently, the activity of free lipase may easily be measured. Free lipase activity can easily be detected when $0.001 \mathrm{~mol}$ dmī 3 EDTA is added to the culture medium. The presence of the chelating agent enhances the production and maintains the stability of the extracted mycelium-bound lipase.
\end{abstract}

Keyword: Aspergillus flavus; Extracellular (free) lipase; Mycelium-bound lipase; Proteases 